\title{
Lisina digestível e zinco orgânico para frangos de corte machos na fase de 22 a 42 dias de idade ${ }^{1}$
}

\author{
Messias Alves da Trindade Neto ${ }^{2}$, Estela Kobashigawa ${ }^{2}$, Lilian Bernadete Namazu², Paula \\ Takeara $^{2}$, Lúcio Francelino Araújo $^{3}$, Ricardo de Albuquerque ${ }^{2}$ \\ 1 Financiamento parcial da Fundação de Apoio à Pesquisa Agrícola - FUNDAG. \\ 2 Departamento de Nutrição e Produção Animal da FMVZ-USP, Campus de Pirassununga, Rua Duque de Caxias Norte, 225, CEP: 13630-000, \\ Pirassununga, SP, Brasil. \\ ${ }^{3}$ Faculdade de Zootecnia e Engenharia de Alimentos - FZEA/USP, Pirassununga, SP, Brasil.
}

RESUMO - Os efeitos dietéticos de lisina digestível e zinco quelato para frangos de corte machos entre 22 e 42 dias de idade foram avaliados em dois ensaios experimentais. Adotou-se o delineamento inteiramente casualizado em arranjo fatorial $5 \times 2$, com cinco níveis de lisina $(0,841 ; 0,876 ; 0,997 ; 1,022$ e 1,030\%) e dois de zinco (43 e 243 ppm). No primeiro ensaio, utilizaram-se 900 aves com peso médio inicial de 957,4 g distribuídas em parcelas experimentais de 30 aves e três repetições e, no segundo ensaio, 180 frangos com peso médio inicial de 866,22 g, divididos em parcelas de três aves e seis repetições. As características avaliadas foram desempenho, rendimento de cortes e composição corporal ( $1^{\circ}$ ensaio), balanço de nitrogênio e digestibilidade aparente das dietas ( $2^{\circ}$ ensaio). Houve interação entre os níveis de lisina e zinco para o ganho de peso, a conversão alimentar, a matéria seca ingerida e o balanço energético. Os rendimentos de peito, coxa e sobrecoxa tiveram aumentos lineares em resposta ao acréscimo no nível de lisina digestível na dieta. O melhor desempenho foi obtido com o nível de 0,997\% de lisina digestível (ou 1,134\% lisina total) e de 43 ppm de zinco. Para maior rendimento dos cortes, o nível de lisina digestível recomendável deve ser no mínimo 1,002\% (ou 1,139\% de lisina total), independentemente dos níveis de zinco quelato. A maior inclusão de zinco em dietas para frangos de corte dos 22 aos 42 dias de idade não melhora a utilização da lisina na dieta e aumenta a deposição de gordura corporal.

Palavras-chave: deposição lipídica, deposição de proteína, desempenho, nitrogênio retido

\section{Digestible lysine and zinc chelate for male broilers from 22 to 42 days of age}

\begin{abstract}
The dietary effects of digestible lysine and chelate zinc for male broiler chickens from 22 to 42 days of age were evaluated in two experimental assays. A complete randomized block experimental design in a $5 \times 2$ factorial, with five lysine levels (0.841, 0.876, 0.997, 1.022 and 1.030\%) and two levels of zinc (43 and $243 \mathrm{ppm}$ ) was used. In the first assay, it was used 900 birds with initial average weight $957.4 \mathrm{~g}$ distributed in experimental units with 30 birds and three replications and in the second assay, 180 broilers with initial average weight $866.22 \mathrm{~g}$ split in plots with 3 birds and six replications were used. The characteristics evaluated were performance, cut yield and body composition ( $1^{\text {st }}$ assay), nitrogen balance and apparent digestibility of diets (2nd assay). There was an interaction among levels of lysine and zinc for weight gain, feed conversion, ingested dry matter and energy balance. Yields of breast, thigh and drumstick had linear increases in response to increments in the level of digestible lysine in the diet. The best performance was obtained for level $0.997 \%$ of digestive lysine (or $1.134 \%$ total lysine) and level of 43 ppm zinc. For higher cut yields, the recommended level of digestible lysine has to be at least $1.002 \%$ (or $1.139 \%$ total lysine), regardless to the levels of chelate zinc. Greater inclusion of zinc in diets for broiler from 22 to 42 days of age does not improve the utilization of dietary lysine and increases body fat deposition.
\end{abstract}

Key Words: lipid deposition, performance, protein deposition, retained nitrogen

\section{Introdução}

A atualização das exigências nutricionais é necessária para melhora do desempenho de animais selecionados para produção de carne. O frango de corte é um bom exemplo das alterações nas demandas nutricionais, devido à contínua ação do melhoramento genético. A diferenciação no crescimento e no aumento de massa muscular do frango coincidiu com mudanças nas demandas por aminoácidos, e a lisina, considerado aminoácido-referência no estabelecimento da relação com os demais aminoácidos, é o principal nutriente associado a esse acréscimo de proteína. Priorizado na formação proteica, a demanda nutricional da lisina é maior nas fases iniciais de crescimento e a eficiência de seu 
uso é associada ao aumento da massa muscular e/ou da retenção de nitrogênio. O correto emprego da lisina e dos demais aminoácidos nas dietas para frangos de corte permite maior eficiência no uso dos nutrientes da dieta e, segundo Azcona et al. (2003), aumenta o rendimento de peito. A determinação do pico de deposição proteica é possibilita estimar a eficiência máxima no uso dos aminoácidos para síntese e acúmulo de massa muscular na carcaça.

O zinco é um mineral-traço essencial ao metabolismo de proteína, carboidratos e gordura e relaciona-se às múltiplas atividades enzimáticas no corpo. Além da divisão celular, síntese de DNA e proteína, o zinco associa-se ao crescimento de tecidos e às funções imune, à produção de prostaglandina e à mineralização óssea (Cheng et al., 1998). Na forma orgânica, o zinco apresenta-se mais biodisponível ao animal em comparação à forma inorgânica (Aoyagi \& Baker, 1993). Hess et al. (2001) estudaram diferentes fontes de zinco em dietas para frangos de corte fêmeas e observaram melhora na conversão alimentar quando utilizaram zinco quelado com aminoácidos. O nível mais baixo do mineral quelatado favoreceu a absorção de nutrientes e o desempenho dos frangos na fase de 0 a 17 dias de idade (Hudson et al., 2005) e teve sua excreção reduzida (Burrell et al., 2004). Na forma orgânica, o zinco torna-se fonte alternativa na nutrição mineral, sem prejudicar o desempenho dos animais.

Objetivou-se neste estudo avaliar o melhor nível dietético de lisina digestível e de zinco quelado, associados ou não, para frangos de corte machos dos 22 aos 42 dias de idade.

\section{Material e Métodos}

A avaliação do desempenho de frangos de corte dos 22 aos 42 dias de idade foi realizada em boxes, no piso de um galpão experimental construído em alvenaria, com aberturas laterais, cortinas para controle da ventilação e equipados com comedouro tubular e bebedouro pendular. No estudo de metabolismo, dos 22 aos 28 dias de idade, as aves foram instaladas em gaiolas de arame galvanizado de $0,90 \times 0,90 \times 0,50 \mathrm{~m}$ a $1 \mathrm{~m}$ de altura do piso. As gaiolas eram providas de comedouro tipo calha, bebedouro nipple e coletor plástico adaptado para recolhimento de excretas. Em ambas as situações, foram instalados termômetros de máxima e mínima, cada um nas extremidades dos galpões para que fossem efetuadas três leituras ao dia. Esse procedimento serviu de auxílio no manejo das cortinas laterais durante o estudo.

Foram utilizadas 1.080 machos de 22 dias de idade, da linhagem Ross. No ensaio de desempenho, 900 aves com peso médio inicial de 957,4 g foram distribuídas em delineamento inteiramente casualizado, em esquema fatorial $5 \times 2$, composto de cinco níveis de lisina digestível $(0,85$; 0,$95 ; 1,05 ; 1,15$; e $1,25 \%$ ) e dois de zinco orgânico (43 e $253 \mathrm{ppm}$ ) na forma de carboaminofosfoquelato de zinco, totalizando 10 tratamentos, cada um avaliado com 3 repetições de 30 aves. No ensaio de metabolismo, 180 frangos com peso médio inicial de $866,2 \mathrm{~g}$ foram distribuídos em mesmo delineamento e os tratamentos aplicados em seis repetições, com a unidade experimental constituída de três aves.

As dietas experimentais (Tabela 1) foram formuladas adotando-se em parte as recomendações de Rostagno et al. (2005) e oferecidas à vontade, de modo que fossem caracterizadas as condições normais do arraçoamento da ave nessa fase do desenvolvimento. As análises dos alimentos e rações foram realizadas no Laboratório de Bromatologia do VNP-FMVZ - Universidade de São Paulo e na Ajinomoto Biolatina Ind. e Com. Ltda (Tabela 2).

Foram considerados na avaliação do desempenho o peso final médio, o ganho de peso médio, o ganho de peso relativo, o consumo médio e a conversão alimentar. O ganho de peso relativo foi obtido pela relação entre o ganho de peso e o peso inicial e foi estudada por associar o ganho de peso no período com o peso inicial. Para efeito de correção do consumo médio de alimento, os dados foram corrigidos de acordo com a mortalidade dentro da unidade experimental.

Para fins comparativos e determinação das taxas de deposição dos componentes químicos corporais ao final do estudo, no início do experimento foram abatidas 10 aves escolhidas aleatoriamente. No $42^{\circ}$ dia, uma ave de cada unidade experimental, representando o peso médio da parcela, foi abatida para determinação da composição química das frações vísceras e sangue, carcaça, corpo vazio e as taxas de deposição de nutrientes corporais. O corpo vazio foi definido como a diferença entre o peso vivo em jejum e o conteúdo gastrintestinal (Susenbeth \& Keitel, 1988).

O abate, a amostragem e a liofilização e moagem para as análises bromatológicas foram feitos segundo procedimentos descritos por Toledo et al. (2007). Na composição química, foram considerados os conteúdos: água, proteína, extrato etéreo e matéria mineral, expressos em gramas ou porcentagem na fração vísceras e sangue, na carcaça e no corpo vazio. Os dados foram apresentados na matéria natural e na matéria seca liofilizada. A partir da composição química corporal, foram determinadas as taxas de deposição de água, protéica, lipídica e mineral na carcaça e no corpo vazio ao final do período experimental (42 dias de idade). 
Tabela 1 - Composição nutricional das dietas experimentais na fase 22 a 42 dias de idade

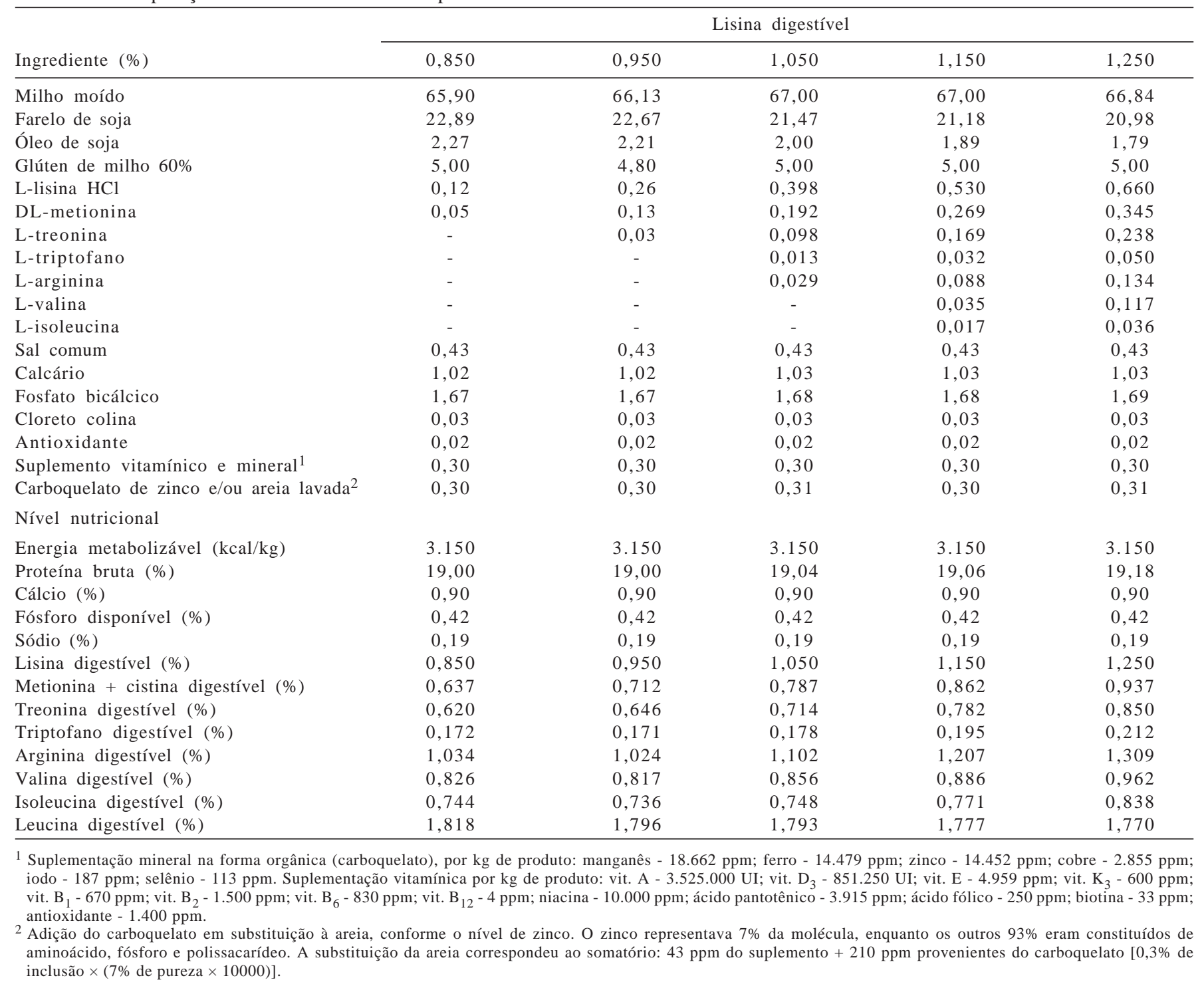

No estudo de metabolismo, a coleta das excretas foi realizada durante dias, após adaptação das aves à dieta por quatro dias. As coletas foram diárias e eram pesadas e congeladas a $-17^{\circ} \mathrm{C}$ até serem preparadas para análises.

Como os valores analisados de aminoácidos foram expressos como totais (Tabela 2), aplicou-se o índice de digestibilidade para estimar a lisina digestível. O índice de correção (87,95\%) baseou-se no estudo de Sebastian et al. (1997) com frangos machos e dietas à base de milho e farelo de soja e na média ponderal dos coeficientes de digestibilidade da lisina total propostos por Rostagno et al. (2005), conforme a inclusão de milho, farelo de soja e glúten nas dietas experimentais.

As análises estatísticas das variáveis experimentais foram realizadas utilizando-se o pacote computacional SAS (2004), General Linear Models (PROC GLM). No fator lisina digestível, adotou-se a regressão polinomial e, para o fator zinco, o teste $\mathrm{F}$. 
Tabela 2 - Valores nutricionais analisados e estimados das dietas fornecidas durante a avaliação de desempenho, rendimento e composição corporal $^{1}$

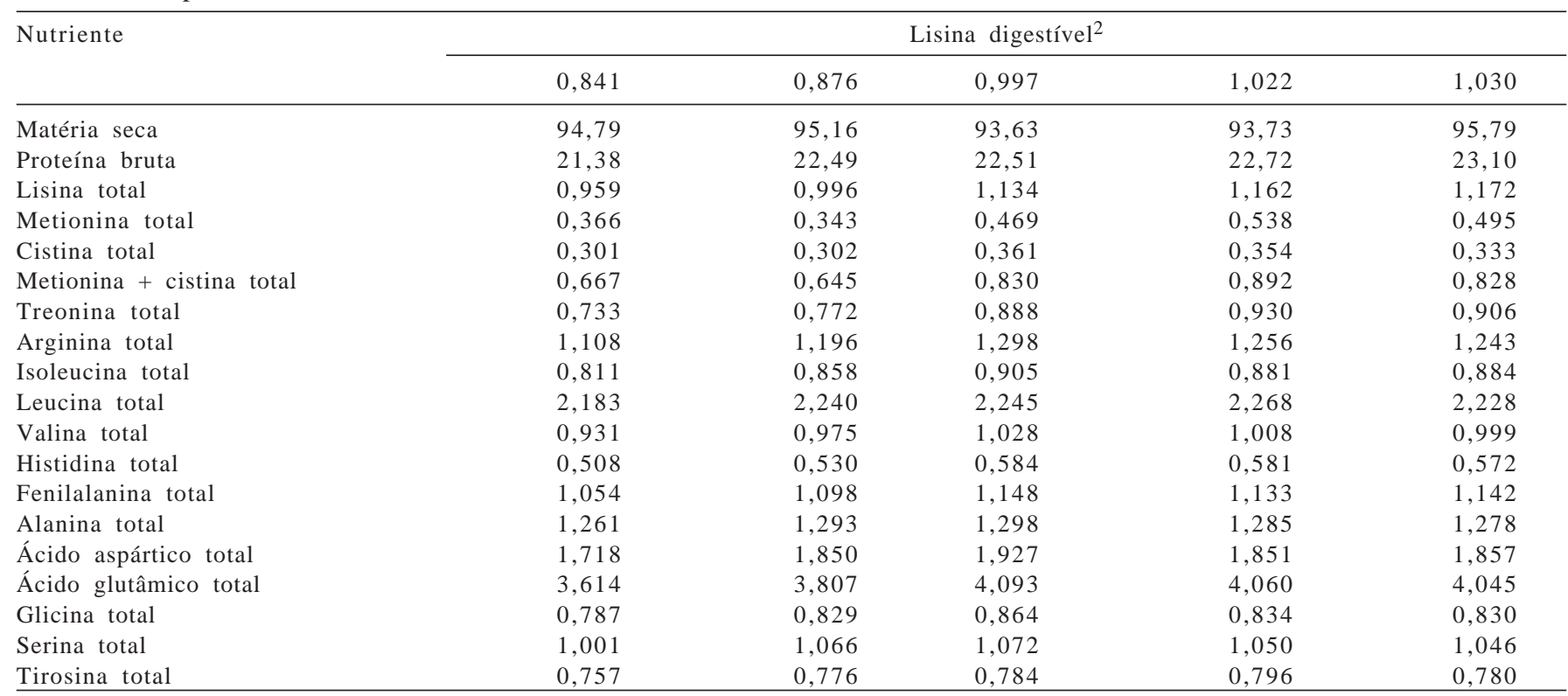

1 Análise realizada pela Ajinomoto Biolatina Indústria e Comércio Ltda.

${ }^{2}$ Lisina digestível estimada por meio do coeficiente de digestibilidade 87,95\%.

\section{Resultados e Discussão}

No primeiro ensaio, a temperatura média foi $24^{\circ} \mathrm{C}$ e umidade relativa média do ar $66 \%$ e, no segundo, as médias foram $26^{\circ} \mathrm{C}$ e $88 \%$, respectivamente. As temperaturas do interior dos galpões variaram de 23 a $29^{\circ} \mathrm{C}$ e 24 a $31^{\circ} \mathrm{C}$, respectivamente.

Na avaliação do desempenho dos frangos dos 22 aos 42 dias de idade (Tabela 3), constatou-se interação $(\mathrm{P}<0,05)$ dos níveis de lisina digestível e zinco no peso médio final e no ganho de peso médio. Segundo os níveis formulados, o aumento da concentração de lisina nas dietas com 43 ppm de zinco quelato favoreceu $(\mathrm{P}<0,05)$ o peso médio final dos frangos até o nível 0,934\% de lisina digestível formulada, segundo a equação $Y=-10220,5656+27713,34569 X-$ $14837,0571 X^{2}, r^{2}=0,20$. Com base nas concentrações analisadas do aminoácido, o melhor nível foi, entretanto, 0,997\% de lisina digestível ou 1,134\% de lisina total. Na concentração de 253 ppm de zinco quelato, o aumento do nível de lisina digestível coincidiu com o acréscimo $(\mathrm{P}<0,05)$ linear do peso médio final $(\mathrm{Y}=2227,2674+428,1332 \mathrm{X}$, $\left.\mathrm{r}^{2}=0,48\right)$ e do ganho de peso médio dos frangos no período de 22 a 42 dias de idade. Na maior concentração de zinco, houve maior efetividade para o acréscimo de lisina, não obstante, os coeficientes de determinação foram baixos para essas características. Da mesma forma, as médias totais não apresentaram diferenças quando foram comparadas as concentrações do mineral. Essa observação coincide com os relatos de Kidd et al. (1992), Bartlett \& Smith (2003) e Burrel et al. (2004), que não constataram efeito do zinco quelato quando usaram concentrações de 80 a 181 ppm em dietas para frangos de corte do $1^{\circ}$ ao $35^{\circ}$ dias de idade.

O ganho de peso relativo, o consumo de ração e a conversão alimentar não tiveram variações significativas com o acréscimo de lisina digestível. No entanto, o nível de 253 ppm de zinco quelato na dieta nos níveis de lisina de 0,876 e $1,03 \%$ teve efeito $(\mathrm{P}<0,05)$ no ganho de peso e na conversão alimentar. No ajuste para ganho de peso relativo, essa mesma variação pode ser sugerida, apesar do maior coeficiente de variação $(\mathrm{P}>0,05)$. Dessa forma, a maior eficiência no aproveitamento dos nutrientes das dietas nesses níveis de lisina parece ter ocorrido quando se elevou a concentração de zinco quelato.

O consumo de ração não foi influenciado pelos níveis de lisina, entretanto, em ambos os níveis de zinco, níveis acima de $0,997 \%$ de lisina digestível promoveram redução $(\mathrm{P}=0,07)$ dessa variável. Essa redução coincide com as demais características de desempenho. Dados de consumo obtidos nesses níveis de lisina digestível, todavia, são controversos. Borges et al. (2002) e Valério et al. (2003), usando aves de idade semelhantes às deste estudo e de linhagens diversas, não observaram efeito do nível de lisina sobre o consumo. Outros autores verificaram que o aumento de lisina na dieta fez com que os frangos diminuíssem o consumo de ração (Fatufe et al., 2004; Sklan \& Noy, 2004). 
Tabela 3 - Desempenho e rendimentos de fígado, coxa + sobrecoxa e peito em frangos de corte aos 42 dias de idade alimentados com rações com cinco níveis de lisina digestível em combinação a dois níveis de zinco quelato

\begin{tabular}{|c|c|c|c|c|c|c|c|c|}
\hline \multirow[t]{2}{*}{ Variável avaliada } & \multirow[t]{2}{*}{ Zinco } & \multicolumn{5}{|c|}{ Lisina digestível $(\%)^{1}$} & \multirow[t]{2}{*}{ Média } & \multirow[t]{2}{*}{ CV (\%) } \\
\hline & & 0,841 & 0,876 & 0,997 & 1,022 & 1,030 & & \\
\hline \multirow[t]{3}{*}{ Peso médio inicial (g) } & 43ppm & 943 & 967 & 968 & 973 & 954 & 961 & \\
\hline & 253рpm & 944 & 958 & 970 & 960 & 936 & 954 & \\
\hline & média & 944 & 962 & 969 & 967 & 945 & 957 & \\
\hline \multirow[t]{4}{*}{ Ganho de peso médio $(\mathrm{g})^{2}$} & 43ppm* & 1699a & $1625 a$ & $1754 \mathrm{a}$ & $1702 \mathrm{a}$ & $1543 b$ & 1664 & 5,09 \\
\hline & 253ppm** & $1666 a$ & $1605 a$ & $1740 \mathrm{a}$ & $1692 \mathrm{a}$ & $1703 a$ & 1681 & 3,25 \\
\hline & média & 1682 & 1615 & 1746 & 1697 & 1623 & 1681 & \\
\hline & CV (\%) & 3,00 & 3,51 & 1,26 & 0,81 & 5,51 & & \\
\hline \multirow[t]{4}{*}{ Ganho de peso relativo } & 43ррm & 1,80 & 1,68 & 1,81 & 1,75 & 1,62 & 1,73 & 6,46 \\
\hline & 253ppm & 1,76 & 1,67 & 1,79 & 1,76 & 1,82 & 1,76 & 4,69 \\
\hline & média & 1,78 & 1,68 & 1,80 & 1,75 & 1,72 & 1,75 & \\
\hline & CV (\%) & 4,47 & 3,93 & 4,53 & 3,09 & 8,80 & & \\
\hline \multirow[t]{4}{*}{ Consumo de ração médio (g) } & 43ррm & 3294 & 3299 & 3355 & 3273 & 3162 & 3277 & 2,56 \\
\hline & 253ppm & 3285 & 3131 & 3356 & 3325 & 3231 & 3266 & 3,48 \\
\hline & média & 3289 & 3215 & 3356 & 3299 & 3197 & 3271 & \\
\hline & CV (\%) & 1,34 & 4,54 & 1,08 & 2,04 & 2,56 & & \\
\hline \multirow[t]{4}{*}{ Conversão alimentar (g) } & 43ppm & $1,94 \mathrm{a}$ & $2,03 a$ & $1,91 \mathrm{a}$ & $1,92 \mathrm{a}$ & $2,05 a$ & 1,97 & 3,61 \\
\hline & 253ppm & $1,97 \mathrm{a}$ & $1,95 b$ & 1,93a & $1,97 a$ & $1,90 \mathrm{~b}$ & 1,94 & 2,30 \\
\hline & média & 1,96 & 1,99 & 1,92 & 1,95 & 1,98 & 1,96 & \\
\hline & CV (\%) & 2,21 & 2,54 & 1,89 & 2,71 & 4,74 & & \\
\hline \multirow[t]{4}{*}{ Fígado (\%) } & 43ppm & 2,19 & 2,09 & 2,17 & 2,16 & 2,22 & 2,17 & 5,77 \\
\hline & 253ppm & 2,03 & 2,12 & 2,12 & 2,12 & 2,05 & 2,09 & 7,73 \\
\hline & média & 2,11 & 2,11 & 2,15 & 2,14 & 2,14 & 2,13 & \\
\hline & CV (\%) & 7,40 & 9,17 & 3,05 & 8,85 & 7,05 & & \\
\hline \multirow[t]{4}{*}{ Coxa + sobrecoxa (\%) } & 43ppm & 23,20 & 23,40 & 22,36 & 22,74 & 22,52 & 22,84 & 2,21 \\
\hline & 253ppm & 23,30 & 22,98 & 22,70 & 22,66 & 23,01 & 22,93 & 3,32 \\
\hline & média & 23,25 & 23,19 & 22,53 & 22,70 & 22,77 & 22,89 & \\
\hline & CV (\%) & 3,40 & 1,76 & 1,86 & 3,40 & 2,44 & & \\
\hline \multirow[t]{4}{*}{ Peito $(\%)^{3}$} & 43ppm & 23,70 & 23,48 & 25,47 & 25,91 & 24,89 & 24,69 & 4,70 \\
\hline & 253ppm & 24,34 & 24,02 & 25,41 & 24,65 & 24,81 & 24,65 & 3,27 \\
\hline & média ${ }^{3}$ & 24,02 & 23,75 & 25,44 & 25,28 & 24,85 & 24,67 & \\
\hline & CV (\%) & 3,34 & 3,35 & 2,67 & 3,72 & 2,00 & & \\
\hline
\end{tabular}

1 Lisina digestível estimada pelo coeficiente de digestibilidade 87,95\%.

2 Indica interação nível de zinco quelato e nível de lisina digestível $(\mathrm{P}<0,05)$.

3 Resposta quadrática do fator lisina $(\mathrm{P}=0,09)$, independentemente do nível de zinco.

* Resposta quadrática $(\mathrm{P}<0,05)$ de lisina na concentração 43 ppm de zinco.

** Resposta linear $(\mathrm{P}<0,05)$ de lisina na concentração de 253 ppm de zinco.

Letras diferentes na mesma coluna diferem entre si para teste $\mathrm{F}(\mathrm{P}<0,05)$ na comparação entre os níveis de zinco.

Não houve interação dos níveis nutricionais estudados nem efeito isolado da concentração de zinco na dieta nos rendimentos de cortes (Tabela 3). Nesse caso, os efeitos sobre o desempenho não corresponderam aos rendimentos de cortes, sugerindo que esse maior ganho correspondeu ao acréscimo de gordura na carcaça. Considerando o nível dezinco dietético, Yamagushi et al.(1988) e Cheng et al.(1998) verificaram que esse mineral estaria associado apenas à síntese proteica do tecido ósseo, portanto, não teria implicações no acréscimo de massa muscular.

O nível de lisina digestível teve efeito quadrático na porcentagem de peito $(\mathrm{P}=0,09)$ : $\mathrm{Y}=7,5125+29,2467 \mathrm{X}-$ $12,0256 \mathrm{X}^{2}\left(\mathrm{r}^{2}=0,76\right)$, que atingiu melhores valores no nível ótimo de 1,216\% do aminoácido, segundo os níveis formulados. Com base nos níveis determinados pela análise de aminoácidos e aplicando-se o coeficiente de digestibilidade de $87,95 \%$ (Tabela 3 ), a concentração de lisina indicada seria $1,002 \%$, portanto, um pouco acima da sugerida para ganho de peso e conversão alimentar. Neste caso, seria caracterizado maior direcionamento da lisina para o crescimento muscular. Efeito semelhante foi sugerido por Borges et al. (2002) e Eits et al. (2003), confirmando que a exigência para o máximo rendimento de peito é superior à demanda considerada para o máximo crescimento.

As variações porcentuais de fígado $(\mathrm{P}=0,07)$ indicam que a maior concentração dietética de aminoácidos coincidiu com aumento das atividades metabólicas nesse órgão, sugerindo provável redução da lipogênese. Aumento do fígado em resposta ao acréscimo de aminoácidos na dieta também foi observado por Leeson \& Zubair (1997)e Swatson et al. (2002), que estudaram níveis de proteína bruta e aminoácidos em dietas para frangos de corte. Como observaram Birkett \& de Lange (2001), se o aumento das atividades hepáticas coincide com a síntese de proteína 
decorrente da suplementação de lisina, haverá maior acúmulo muscular na carcaça e menor catabolismo proteico. Em situação contrária, quando a proteína é usada para produção de energia, o gasto energético torna-se maior, em comparação à síntese, pois exige 4 a 7 mol de ATP por peptídeo formado e 1 a 2 mol de ATP por peptídeo "quebrado".

$\mathrm{Na}$ composição química corporal dos frangos aos 42 dias de idade (Tabela 4), constatou-se interação $(\mathrm{P}<0,05)$ do

Tabela 4 - Composição química da carcaça e do corpo vazio em frangos de corte aos 42 dias de idade alimentados com dietas com cinco níveis de lisina e dois de zinco quelato

\begin{tabular}{|c|c|c|c|c|c|c|c|c|}
\hline \multirow[t]{2}{*}{ Item } & \multirow[t]{2}{*}{ Zinco (ppm) } & \multicolumn{5}{|c|}{ Lisina digestível $(\%)^{1}$} & \multirow[t]{2}{*}{ Média } & \multirow[t]{2}{*}{ CV (\%) } \\
\hline & & 0,841 & 0,876 & 0,997 & 1,022 & 1,030 & & \\
\hline \multirow[t]{4}{*}{ Peso da ave em jejum (g) } & 43 & 2623 & 2567 & 2712 & 2637 & 2507 & 2609 & 3,66 \\
\hline & 253 & 2640 & 2510 & 2770 & 2668 & 2662 & 2650 & 4,27 \\
\hline & média & 2632 & 2538 & 2741 & 2653 & 2584 & 2630 & \\
\hline & CV (\%) & 0,89 & 3,03 & 3,10 & 3,19 & 4,76 & & \\
\hline \multirow[t]{4}{*}{ Peso carcaça (g) } & 43 & 2228 & 2185 & 2274 & 2154 & 2105 & 2189 & 4,09 \\
\hline & 253 & 2217 & 2105 & 2338 & 2268 & 2299 & 2245 & 4,88 \\
\hline & média & 2222 & 2145 & 2306 & 2211 & 2202 & 2217 & \\
\hline & CV (\%) & 1,60 & 3,43 & 3,70 & 4,80 & 6,36 & & \\
\hline \multirow[t]{4}{*}{ Água na carcaça (\%) } & 43 & $66,79 a$ & $64,37 b$ & $67,13 a$ & $67,53 a$ & $66,54 a$ & 66,47 & 1,92 \\
\hline & 253 & $65,39 a$ & $66,81 \mathrm{a}$ & $66,03 a$ & $66,00 \mathrm{~b}$ & $67,27 a$ & 66,30 & 1,70 \\
\hline & média & 66,09 & 65,59 & 66,58 & 66,77 & 66,91 & 66,39 & \\
\hline & CV (\%) & 1,85 & 2,45 & 1,08 & 1,61 & 1,50 & & \\
\hline \multirow[t]{4}{*}{ Água no corpo vazio $(\%)^{2}$} & $43 *$ & $67,39 a$ & $65,40 \mathrm{~b}$ & $68,23 a$ & $68,46 a$ & $67,73 a$ & 67,44 & 1,90 \\
\hline & 253 & $66,28 a$ & $67,45 a$ & $66,62 b$ & $66,91 b$ & $67,75 a$ & 67,00 & 1,58 \\
\hline & média & 66,84 & 66,43 & 67,43 & 67,69 & 67,74 & & \\
\hline & CV (\%) & 1,69 & 2,30 & 1,39 & 1,54 & 1,39 & & \\
\hline \multirow[t]{4}{*}{ Extrato etéreo na carcaça (\%) } & 43 & 14,22 & 16,33 & 12,50 & 11,84 & 13,47 & 13,68 & 12,89 \\
\hline & 253 & 15,36 & 13,15 & 14,28 & 14,73 & 12,65 & 14,04 & 10,49 \\
\hline & média & 14,79 & 14,76 & 13,39 & 13,28 & 13,06 & & \\
\hline & CV (\%) & 7,21 & 15,48 & 8,55 & 12,86 & 7,44 & & \\
\hline \multirow[t]{4}{*}{ Extrato etéreo no corpo vazio $(\%)^{2}$} & $43 *$ & $14,13 a$ & $15,81 a$ & $12,36 b$ & $11,71 b$ & $13,03 a$ & 13,41 & 12,68 \\
\hline & 253 & $15,17 \mathrm{a}$ & $13,21 b$ & $14,5 \mathrm{a}$ & $14,47 a$ & $12,70 \mathrm{a}$ & 14,01 & 10,12 \\
\hline & média & 14,65 & 14,51 & 13,43 & 13,09 & 12,87 & 13,71 & \\
\hline & CV (\%) & 7,06 & 14,45 & 9,49 & 13,29 & 7,33 & & \\
\hline \multirow[t]{4}{*}{ Proteína bruta na carcaça $(\%)^{2}$} & $43 *$ & 15,55 & 15,34 & 16,48 & 17,15 & 16,64 & 16,23 & 6,67 \\
\hline & 253 & 15,67 & 16,56 & 15,87 & 15,59 & 17,03 & 16,14 & 6,07 \\
\hline & média & 15,61 & 15,95 & 16,18 & 16,37 & 16,84 & & \\
\hline & CV (\%) & 5,96 & 6,32 & 3,85 & 7,35 & 6,66 & & \\
\hline \multirow[t]{4}{*}{ Proteína bruta no corpo vazio (\%) } & 43 & 15,30 & 15,21 & 15,85 & 16,67 & 16,17 & 15,84 & 5,51 \\
\hline & 253 & 15,27 & 16,13 & 15,36 & 15,28 & 16,68 & 15,74 & 5,84 \\
\hline & média & 15,29 & 15,67 & 15,61 & 15,98 & 16,43 & 15,79 & \\
\hline & CV (\%) & 5,39 & 5,73 & 3,43 & 6,71 & 5,12 & & \\
\hline \multirow[t]{4}{*}{ Matéria mineral na carcaça (\%) } & 43 & 3,45 & 3,92 & 3,88 & 3,48 & 3,34 & 3,62 & 15,40 \\
\hline & 253 & 3,58 & 3,48 & 3,81 & 3,67 & 3,05 & 3,52 & 12,09 \\
\hline & média & 3,51 & 3,70 & 3,84 & 3,57 & 3,19 & & \\
\hline & CV (\%) & 9,98 & 14,99 & 6,39 & 10,04 & 21,78 & & \\
\hline \multirow[t]{4}{*}{ Matéria mineral no corpo vazio $(\%)^{3}$} & 43 & 3,18 & 3,58 & 3,56 & 3,16 & 3,07 & 3,31 & 14,64 \\
\hline & 253 & 3,28 & 3,21 & 3,52 & 3,34 & 2,87 & 3,24 & 11,18 \\
\hline & média & 3,23 & 3,40 & 3,54 & 3,25 & 2,97 & 3,28 & \\
\hline & CV (\%) & 9,11 & 13,94 & 5,83 & 9,98 & 20,09 & & \\
\hline \multirow[t]{4}{*}{ Víscera vazia (g) } & 43 & 345,6 & 327,7 & 353,2 & 364,2 & 344,7 & 347,1 & 7,74 \\
\hline & 253 & 347,4 & 338,1 & 366,7 & 340,2 & 315,1 & 341,5 & 7,49 \\
\hline & média & 346,5 & 332,9 & 359,9 & 352,2 & 329,9 & 344,3 & \\
\hline & CV (\%) & 8,93 & 6,00 & 5,75 & 7,76 & 7,34 & & \\
\hline \multirow[t]{4}{*}{ Extrato etéreo (\%) } & 43 & 13,60 & 12,13 & 11,46 & 11,03 & 10,35 & 11,7b & 18,33 \\
\hline & 253 & 13,90 & 13,56 & 15,88 & 12,74 & 13,00 & $13,8 \mathrm{a}$ & 14,49 \\
\hline & média & 13,75 & 12,85 & 13,67 & 11,89 & 11,68 & 12,77 & \\
\hline & CV (\%) & 13,91 & 18,23 & 17,97 & 22,21 & 17,28 & & \\
\hline \multirow[t]{4}{*}{ Proteína bruta (\%) } & 43 & 47,75 & 51,87 & 47,66 & 53,39 & 53,30 & $50,8 \mathrm{a}$ & 9,96 \\
\hline & 253 & 45,62 & 47,33 & 40,86 & 48,95 & 49,21 & $46,4 b$ & 10,74 \\
\hline & média & 46,7 & 49,6 & 44,3 & 51,2 & 51,3 & 48,59 & \\
\hline & CV (\%) & 10,04 & 11,50 & 8,59 & 13,49 & 5,86 & & \\
\hline
\end{tabular}

${ }^{1}$ Lisina digestível estimada por meio do coeficiente de digestibilidade 87,95\%.

2 Indica interação $(\mathrm{P}<0,05)$ entre o nível de zinco quelato e o de lisina digestível.

3 Resposta quadrática do fator lisina $(\mathrm{P}<0,05)$, independentemente do nível de zinco.

* Resposta linear $(\mathrm{P}<0,05)$ de lisina na concentração 43 ppm de zinco.

Letras diferentes na mesma coluna diferem entre si pelo teste $\mathrm{F}(\mathrm{P}<0,05)$ na comparação entre os níveis de zinco. 
nível de lisina digestível e zinco. Para as aves que receberam 43 ppm de zinco, a variação de lisina digestível sugere redução linear da gordura no corpo vazio segundo a equação $\mathrm{Y}=27,6055-14,9214 \mathrm{X}\left(\mathrm{r}^{2}=0,65\right)$. Nessa mesma concentração do mineral, a variação da concentração de lisina digestível coincidiu com aumento linear da proteína bruta ( $Y=15,4384$ $\left.+34,7841 \mathrm{X}, \mathrm{r}^{2}=0,67\right)$ na carcaça e na composição de água do corpo vazio ( $\left.\mathrm{Y}=58,4391+9,4565 \mathrm{X}, \mathrm{r}^{2}=0,46\right)$.

No maior ou menor nível de zinco, há indicação de que o aumento de lisina na dieta elevou a porcentagem de proteína, diminuindo o extrato etéreo. Os frangos que receberam 43 ppm do zinco apresentaram maior acúmulo $(\mathrm{P}<0,05)$ de água no corpo vazio, coincidindo também com o menor $(\mathrm{P}<0,05)$ acréscimo de gordura. Esse efeito confirma informações de que o aumento da água no corpo vazio coincide com acréscimo da proteína e à diminuição do acúmulo de gordura. Segundo Claus \& Weiler (1994), no tecido magro, a fração de água corresponde a $3 / 4$, enquanto a proteica é apenas $1 / 4$. Assim, o efeito do aumento na deposição proteica fica caracterizado pelo aumento de água na composição corpórea. Da mesma forma, a redução da gordura corporal sugere aumento na eficiência da síntese proteica e acúmulo de massa muscular.

Na matéria mineral da carcaça e do corpo vazio, observou-se resposta quadrática para o aumento do nível dietético de lisina, segundo as equações: $\mathrm{Y}=-63,9624+$ $146,1278 X-78,4571 X^{2}\left(r^{2}=0,74\right) ;$ e $Y=-57,3027+131,0633$ $X-70,3537 X^{2}\left(r^{2}=0,77\right)$ respectivamente. Com base na composição da carcaça e do corpo vazio, o nível digestível do aminoácido dietético estimado como ótimo seria 0,931 a 0,932\%, entretanto esse parâmetro não é o ideal para avaliar eficiência no uso da proteína na deposição muscular da carcaça.

Os níveis de lisina digestível não afetaram as porcentagens de extrato etéreo e proteína bruta nas vísceras e no sangue. A ausência de variação significativa confirma que a lisina não é direcionada para o sangue e as vísceras (Trindade Neto et al., 2009). A concentração de zinco, no entanto, foi determinante na composição média do extrato etéreo e da proteína dessa fração (vísceras e sangue). $\mathrm{Na}$ concentração de 253 ppm de zinco, houve aumento $(\mathrm{P}<0,05)$ do extrato etéreo, enquanto na concentração de 43 ppm aumentou-se $(\mathrm{P}<0,05)$ a concentração de proteína nas vísceras.

Nos dados referentes à deposição corporal dos nutrientes (Tabela 5), constatou-se interação $(P<0,05)$ entre os níveis de lisina e zinco na deposição lipídica da carcaça e do corpo vazio. A deposição lipídica foi menos pronunciada $(\mathrm{P}<0,05)$ quando os frangos consumiram dietas com 43 ppm de zinco, em comparação às dietas com 253 ppm. No nível de 43 ppm, o aumento da concentração de lisina correspondeu à redução linear $(\mathrm{P}<0,05)$ do acúmulo lipídico na carcaça e no corpo vazio, conforme equações $\mathrm{Y}=595,5478-371,2310 \mathrm{X}\left(\mathrm{r}^{2}=0,68\right) \mathrm{e}=663,4087-405,8966 \mathrm{X}$ $\left(r^{2}=0,76\right)$, respectivamente.

O aumento da deposição lipídica nas vísceras e no corpo, decorrente da maior suplementação de zinco pode corresponder às informações de Chen et al. (1996) e Tallman \& Taylor (2003), que sugeriram a inter-relação do mineral com o aumento da obesidade em ratos adultos. Esses autores relataram que ratos adultos absorveram mais zinco, coincidindo com a maior deposição do mineral no fígado e tecido adiposo. A maior absorção intestinal favoreceu o acúmulo de ácidos graxos, numa fase em que o crescimento de massa muscular é limitado pela idade. Diferentemente, ratos jovens não apresentaram essas respostas ao aumento do zinco, pois o tecido muscular não estaria associado à estocagem de energia. Essas observações em ratos podem, provavelmente, ser aplicadas a este estudo, visto que os frangos se encontravam na fase, cujo acúmulo de gordura tende a descrescer. Em estudo preliminar, Namazu et al.(2008) notaram que, em maior concentração dietética, o zinco orgânico proporcionou melhor resposta no aproveitamento da energia ingerida, ao avaliarem dietas com as mesmas concentrações de zinco deste estudo para frangos de corte, da mesma linhagem e sexo, na primeira semana de vida.

Na deposição proteica da carcaça e do corpo vazio, o acréscimo do nível de lisina propiciou aumento linear, segundo as equações $Y=105,9582+144,9115 X\left(r^{2}=0,80\right)$ e $\mathrm{Y}=133,3812+142,4793 \mathrm{X}\left(\mathrm{r}^{2}=0,86\right)$, respectivamente. Esses dados sugerem que a exigência para máxima deposição seja igual ou acima de 1,030\% de lisina digestível ou 1,172 de lisina total, portanto, acima do nível indicado no desempenho e rendimento de peito. Segundo Bartov \& Plavnik (1998) e Kolling et al. (2005), a produção de carne nas linhagens modernas de frangos de corte pode ser aumentada para fornecer dieta com nível de proteína moderadamente elevado e composição aminoacídica balanceada. Dessa forma, a deposição aumenta e a relação síntese:deposição diminui (Birkett \& Lange, 2001).

Na relação proteína bruta:extrato etéreo do corpo vazio, evidenciou-se a interação de lisina e zinco. Na concentração 43 ppm de zinco, o aumento foi linear segundo equação $\mathrm{Y}=-0,480324713+1,771765868 \mathrm{X}\left(\mathrm{r}^{2}=0,71\right)$, o que indica melhor uso da lisina para deposição proteica, confirmando a prioridade do aminoácido no acúmulo de massa muscular esquelética. Isso sugere também que a demanda pelo aminoácido para síntese proteica parece ser maior que a 
exigência para desempenho, coincidindo-se, simultaneamente, com a redução da deposição lipídica.

A deposição de matéria mineral na carcaça e no corpo vazio variou segundo as equações $\mathrm{Y}=-1600,0925+$ $3606,2775-1931,0675 X^{2}\left(r^{2}=0,57\right)$ e $Y=-1665,1133+$ $3754,1490 X-2009,9450 X^{2}\left(r^{2}=0,56\right)$, respectivamente. Com base nos níveis formulados, ambas as equações indicam 0,934\% de lisina digestível, coincidindo, aproximadamente, a 1,134\% total ou 0,977\% digestível do aminoácido analisado e corrigido pelo índice de digestibilidade, respectivamente, observados para as características de desempenho.

Na avaliação da digestibilidade aparente das dietas (ensaio 2) (Tabela 6), houve interação de lisina e zinco quelato. Na concentração de 43 ppm de zinco, o aumento do nível de lisina na dieta favoreceu o consumo de matéria seca até o nível 0,998\% de lisina digestível (formulada) segundo a equação $\mathrm{Y}=-18,2158+767,7071 \mathrm{X}-384,6237 \mathrm{X}^{2}, \mathrm{r}^{2}=0,69$. Os níveis estimados equivalentes foram $0,948 \%$ de lisina digestível ou 1,077\% de lisina total. Concentrações acima prejudicaram o consumo de matéria seca, como relatado por
Sklan \& Noy (2004), que o excesso de lisina prejudica a ingestão.

O teor de lisina nas dietas com 253 ppm de zinco quelato seguiu a equação $\mathrm{Y}=706,2644-727,7094 \mathrm{X}+$ $360,0604 X^{2}, r^{2}=0,93$. A ingestão diminuiu com o aumento de lisina digestível até o nível de 1,010\% e a partir desse nível ocorreu resposta favorável ao aumento de lisina digestível na dieta. Nesse nível de zinco, os frangos responderam positivamente às maiores concentrações de lisina digestível, sem prejuízos no consumo. A diferença entre os níveis de zinco no consumo de matéria seca, no entanto, não correspondeu a melhorias na porcentagem do nitrogênio retido. A ingestão de matéria seca, por si só, não indica melhor suplementação de zinco quelato, pois as médias não diferiram $(\mathrm{P}>0,05)$ entre os níveis de zinco quelato.

A digestibilidade da matéria seca não foi alterada pelos níveis de lisina digestível e zinco quelato, evidenciando que nos níveis empregados, tanto o zinco quelato quanto a lisina digestível não afetaram a variável.

Tabela 5 - Deposição de nutrientes na carcaça e no corpo vazio de frangos de corte aos 42 dias de idade alimentados com dietas com cinco níveis de lisina digestível e dois de zinco quelato

\begin{tabular}{|c|c|c|c|c|c|c|c|c|}
\hline \multirow[t]{2}{*}{ Item } & \multirow[t]{2}{*}{ o $(\mathrm{ppm})$} & \multicolumn{5}{|c|}{ Lisina digestível $(\%)^{1}$} & \multirow[t]{2}{*}{ Média } & \multirow[t]{2}{*}{$\mathrm{CV}(\%)$} \\
\hline & & 0,841 & 0,876 & 0,997 & 1,022 & 1,030 & & \\
\hline \multirow[t]{4}{*}{ Extrato etéreo na carcaça $(g)^{2}$} & $43 *$ & $259,7 a$ & $300,7 a$ & $227,0 \mathrm{~b}$ & $197,7 \mathrm{~b}$ & $226,6 a$ & 242,4 & 17,24 \\
\hline & 253 & $283,5 a$ & $220,2 b$ & $276,1 \mathrm{a}$ & $276,5 a$ & $233,3 a$ & 257,9 & 13,56 \\
\hline & média & 271,6 & 260,5 & 251,6 & 237,1 & 230,0 & 250,2 & \\
\hline & CV (\%) & 9,60 & 21,95 & 11,35 & 19,00 & 9,83 & & \\
\hline \multirow[t]{4}{*}{ Proteína na carcaça $(\mathrm{g})^{3}$} & 43 & 231,4 & 220,1 & 259,8 & 254,7 & 234,9 & 240,2 & 10,48 \\
\hline & 253 & 231,8 & 233,3 & 256,5 & 239,0 & 276,8 & 247,5 & 11,62 \\
\hline & média & 231,6 & 226,7 & 258,1 & 246,8 & 255,9 & 243,8 & \\
\hline & CV (\%) & 6,61 & 6,90 & 9,16 & 12,16 & 13,93 & & \\
\hline \multirow[t]{4}{*}{ Mineral na carcaça $(g)^{4}$} & 43 & 68,9 & 78,1 & 80,4 & 67,1 & 62,3 & 71,4 & 18,29 \\
\hline & 253 & 71,4 & 65,4 & 81,2 & 75,2 & 62,0 & 71,0 & 13,20 \\
\hline & média & 70,2 & 71,8 & 80,8 & 71,1 & 62,2 & 71,2 & \\
\hline & CV (\%) & 9,37 & 19,88 & 6,94 & 11,54 & 20,85 & & \\
\hline \multirow[t]{4}{*}{ Extrato etéreo no corpo vazio ${ }^{2}$} & $43 *$ & $300,8 a$ & $335,0 \mathrm{a}$ & $261,9 b$ & $231,8 b$ & $256,6 a$ & $277,2 b$ & 16,13 \\
\hline & 253 & $326,4 a$ & $260,9 b$ & $328,8 \mathrm{a}$ & $314,3 a$ & 268,9 a & 299,9 a & 8,99 \\
\hline & média & 313,6 & 298,0 & 295,4 & 273,1 & 262,8 & 288,6 & \\
\hline & CV (\%) & 7,64 & 6,47 & 9,17 & 12,35 & 11,51 & & \\
\hline \multirow[t]{4}{*}{ Proteína no corpo vazio ${ }^{3}$} & 43 & 258,4 & 246,5 & 281,0 & 284,7 & 260,3 & 266,2 & 9,97 \\
\hline & 253 & 255,6 & 258,2 & 280,4 & 263,5 & 300,7 & 271,7 & 10,66 \\
\hline & média & 257,0 & 252,3 & 280,7 & 274,1 & 280,5 & 268,9 & \\
\hline & CV (\%) & 7,65 & 6,47 & 9,17 & 12,35 & 11,51 & & \\
\hline \multirow[t]{4}{*}{ Mineral no corpo vazio ${ }^{4}$} & 43 & 72,9 & 81,2 & 84,5 & 70,8 & 65,9 & 75,1 & 17,08 \\
\hline & 253 & 75,1 & 69,4 & 86,3 & 78,0 & 65,8 & 74,9 & 13,09 \\
\hline & média & 74,0 & 75,3 & 85,4 & 74,4 & 65,9 & 75,0 & \\
\hline & CV (\%) & 9,28 & 18,41 & 6,43 & 10,68 & 19,54 & & \\
\hline \multirow[t]{4}{*}{ Relação proteína bruta/extrato etéreo ${ }^{2}$} & $43 *$ & $1,09 \mathrm{a}$ & $0,96 b$ & $1,29 \mathrm{a}$ & $1,44 \mathrm{a}$ & $1,25 \mathrm{a}$ & 1,21 & 17,43 \\
\hline & 253 & 1,01a & $1,26 a$ & $1,06 \mathrm{a}$ & $1,06 \mathrm{~b}$ & 1,33a & 1,14 & 17,49 \\
\hline & média & 1,05 & 1,11 & 1,18 & 1,25 & 1,29 & 1,18 & \\
\hline & CV (\%) & 11,19 & 24,09 & 12,63 & 20,42 & 11,76 & & \\
\hline
\end{tabular}

${ }^{1}$ Lisina digestível estimada pelo coeficiente de digestibilidade 87,95\%.

2 Indica interação $(\mathrm{P}<0,05)$ nível de zinco quelato e nível de lisina digestível.

${ }^{3}$ Resposta linear do fator lisina $(\mathrm{P}<0,05)$, independentemente do nível de zinco.

${ }^{4}$ Resposta quadrática do fator lisina $(\mathrm{P}<0,05)$, independentemente do nível de zinco.

* Resposta linear $(\mathrm{P}<0,05)$ de lisina na concentração 43 ppm de zinco.

Letras diferentes na mesma coluna diferem entre si para teste $\mathrm{F}(\mathrm{P}<0,05)$ na comparação entre zinco. 
O aumento linear da ingestão de nitrogênio com a maior concentração de lisina nas dietas com 43 ppm de zinco era esperado. Nesse caso, obedeceu a equação $Y=5,0527+$ $2,8868 \mathrm{X}\left(\mathrm{r}^{2}=0,74\right)$. Na dieta com 273 ppm de zinco, houve resposta quadrática ao aumento do nível de lisina, segundo equação $\mathrm{Y}=28,5441-34,3341 \mathrm{X}+17,9084 \mathrm{X}^{2}, \mathrm{r}^{2}=0,72$. $\mathrm{O}$ nível estimado da lisina digestível para menor ingestão de nitrogênio nas dietas com maior quantidade de zinco foi 0,959\% (0,882\% digestível e 1,003\% total com base nos dados analisados).

O nitrogênio retido, expresso em valor absoluto, teve aumento linear com a variação crescente de lisina digestível na dieta, segundo a equação $Y=5,0527+2,8868 X\left(r^{2}=0,74\right)$. Os valores observados não dependem do nível de zinco, no entanto, quando expresso em valores relativos, o nitrogênio retido não foi influenciado pelos níveis de lisina. O aumento na concentração do aminoácido não interferiu na retenção nitrogênio, pois o valor absoluto esteve relacionado apenas à quantidade de nitrogênio ingerido. Do nitrogênio ingerido, cerca de $45 \%$ foi retido. Esse valor confirma a observação feita por Cauwenberghe \& Burnham (2001) de que 55\% do nitrogênio ingerido é excretado pelo frango. Na matéria seca ingerida, a retenção média do nitrogênio não diferiu entre os níveis de zinco, caracterizando ausência de efeito da concentração do mineral.

Houve interação de lisina e zinco nos níveis de energia bruta ingerida e energia excretada e no balanço energético (Tabela 6). No nível 43 ppm de zinco, a variação na ingestão de energia ocorreu segundo a equação $\mathrm{Y}=-251,6150+$ $3889,3790 X-1960,5410 X^{2}\left(r^{2}=0,66\right)$ conforme aumentou a lisina na dieta. Na concentração 253 ppm do mineral quelato, a equação correspondente foi $Y=3067,1720-2963,4781 X$ $+1452,8213 X^{2}\left(r^{2}=0,99\right)$. Essas respostas ratificam as observações sobre a ingestão de matéria seca. Na dieta com 43 ppm de zinco, a maior ingestão ocorreu no nível estimado de $0,992 \%$ de lisina digestível (1,049\% total ou $0,923 \%$

Tabela 6 - Digestibilidade e valores de energia de dietas contendo cinco níveis de lisina digestível e dois de zinco quelato para frangos de corte dos 21 aos 32 dias de idade (com base na matéria seca/ave/dia)

\begin{tabular}{|c|c|c|c|c|c|c|c|c|}
\hline \multirow[t]{2}{*}{ Item } & \multirow[t]{2}{*}{ Zinco (ppm) } & \multicolumn{5}{|c|}{ Lisina digestível $(\%)^{1}$} & \multirow[t]{2}{*}{ Média } & \multirow[t]{2}{*}{ CV (\%) } \\
\hline & & 0,841 & 0,876 & 0,997 & 1,022 & 1,030 & & \\
\hline \multirow[t]{4}{*}{ Matéria seca ingerida $(\mathrm{g})^{1}$} & $43 * *$ & $113,2 \mathrm{a}$ & $120,9 \mathrm{a}$ & $120,7 \mathrm{~b}$ & $120,5 b$ & $115,5 \mathrm{a}$ & 118.2 & 4,95 \\
\hline & $253 * *$ & 119,9 & 116,5 & 112,4 & 114,3 & 117,9 & 116,2 & 4,49 \\
\hline & média & 116,5 & 118,7 & 116,5 & 117,4 & 116,7 & 117,2 & \\
\hline & CV (\%) & 6,25 & 4,38 & 5,31 & 4,27 & 3,84 & & \\
\hline \multirow[t]{4}{*}{ Matéria seca digestível (\%) } & 43 & 76,34 & 75,65 & 75,21 & 74,87 & 74,81 & 75,38 & 2,32 \\
\hline & 253 & 75,12 & 75,72 & 74,77 & 78,01 & 75,56 & 75,84 & 3,61 \\
\hline & média & 75,73 & 75,69 & 74,99 & 76,44 & 75,19 & 75,61 & \\
\hline & CV (\%) & 3,30 & 3,62 & 1,88 & 4,10 & 1,51 & & \\
\hline \multirow[t]{4}{*}{ Nitrogênio ingerido $(g)^{1}$} & $43 *$ & $4,06 b$ & $4,16 a$ & $4,45 a$ & $4,25 a$ & $4,36 a$ & 4,26 & 5,26 \\
\hline & $253 * *$ & $4,30 \mathrm{a}$ & $4,00 \mathrm{a}$ & $4,14 b$ & 4,03b & $4,45 a$ & 4,19 & 5,63 \\
\hline & média & 4,18 & 4,08 & 4,29 & 4,14 & 4,41 & 4,22 & \\
\hline & CV (\%) & 6,25 & 4,37 & 5,31 & 4,27 & 3,85 & & \\
\hline \multirow[t]{4}{*}{ Nitrogênio retido $(g)^{2}$} & 43ppm & 2,41 & 2,42 & 2,88 & 2,65 & 2,81 & 2,63 & 10,76 \\
\hline & 253ppm & 2,53 & 2,29 & 2,64 & 2,68 & 2,87 & 2,60 & 11,22 \\
\hline & média & 2,47 & 2,36 & 2,76 & 2,67 & 2,84 & 2,62 & \\
\hline & CV (\%) & 11,18 & 8,35 & 7,34 & 10,06 & 6,41 & & \\
\hline \multirow[t]{4}{*}{ Energia bruta (EB) ingerida $(\mathrm{kcal})^{1}$} & $43 * *$ & $517,2 b$ & $557,3 \mathrm{a}$ & $558,3 \mathrm{a}$ & $549,0 \mathrm{a}$ & $527,0 \mathrm{a}$ & 541,8 & 5,18 \\
\hline & $253 * *$ & $547,1 \mathrm{a}$ & $536,7 a$ & $519,8 b$ & $420,4 b$ & $538,2 \mathrm{a}$ & 512,4 & 4,35 \\
\hline & média & 532,1 & 547,0 & 539,1 & 484,7 & 532,7 & 527,1 & \\
\hline & CV (\%) & 6,25 & 4,39 & 5,32 & 4,27 & 3,85 & & \\
\hline \multirow[t]{4}{*}{ Energia excretada $(\mathrm{kcal})^{1}$} & $43 * *$ & $102,1 \mathrm{~b}$ & $116,2 \mathrm{a}$ & $117,9 \mathrm{a}$ & $118,6 \mathrm{a}$ & $114,7 \mathrm{a}$ & 113,9 & 9,32 \\
\hline & $253 * *$ & $117,2 \mathrm{a}$ & $111,2 \mathrm{a}$ & $114,6 a$ & $98,5 b$ & $113,1 \mathrm{a}$ & 110,9 & 14,08 \\
\hline & média & 109,6 & 113,7 & 116,2 & 108,6 & 113,9 & 112,4 & \\
\hline & CV (\%) & 14,84 & 13,27 & 7,48 & 15,73 & 6,00 & & \\
\hline \multirow[t]{4}{*}{ Energia metabolizável (kcal/dia) ${ }^{1}$} & $43 *$ & 407,0 & 405,1 & 405,3 & 396,6 & 396,8 & 402,2 & 2,40 \\
\hline & 253 & 399,0 & 405,9 & 400,8 & 410,2 & 400,6 & 403,3 & 3,26 \\
\hline & média & 403,0 & 405,5 & 403,0 & 403,4 & 398,7 & 402,7 & \\
\hline & CV (\%) & 3,27 & 3,26 & 1,97 & 3,75 & 1,5 & & \\
\hline \multirow[t]{4}{*}{ Balanço energético (kcal) ${ }^{1}$} & $43 * *$ & $415,08 a$ & $441,14 \mathrm{a}$ & $440,37 a$ & $430,40 a$ & $412,48 a$ & 427,89 & 6,02 \\
\hline & 253 & $430,00 \mathrm{a}$ & $425,53 a$ & $405,27 b$ & $421,91 \mathrm{a}$ & $425,20 a$ & 421,58 & 5,05 \\
\hline & média & 422,54 & 433,34 & 422,82 & 426,16 & 418,84 & 424,74 & \\
\hline & CV (\%) & 6,77 & 5,23 & 6,31 & 5,13 & 4,43 & & \\
\hline
\end{tabular}

${ }^{1}$ Indica interação $(\mathrm{P}<0,05)$ nível de zinco quelato e nível de lisina digestível.

2 Resposta quadrática ao nível de lisina $(\mathrm{P}<0,05)$ da dieta, independentemente do nível de zinco.

* Resposta linear $(\mathrm{P}<0,05)$ à lisina na concentração de zinco. ** Resposta quadrática $(\mathrm{P}<0,05)$ à lisina digestível na concentração de zinco.

Letras diferentes na mesma coluna diferem entre si para teste $\mathrm{F}(\mathrm{P}<0,05)$ na comparação entre os níveis de zinco. 
digestível corrigidos pela análise e pelo índice de digestibilidade), enquanto, na dieta com 253 ppm, a menor ingestão foi observada no nível estimado de 1,020\% de lisina digestível $(1,101 \%$ total ou $0,968 \%$ digestível corrigido). Como ocorreu no ensaio de desempenho, a maior necessidade aparente de lisina com o aumento na concentração de zinco não corresponde à maior eficiência no uso do aminoácido pela ave.

Na dieta com 43 ppm de zinco quelato, as variações na energia bruta excretada e no balanço energético com o aumento de lisina digestível tiveram efeito quadrático, segundo as respectivas equações $Y=-95,9045+413,3027 \mathrm{X}-$ $197,6693 X^{2}\left(r^{2}=0,72\right)$ e $Y=-477,5843+1914,5033 X-$ $975,0923 X^{2}\left(r^{2}=0,64\right)$. Os níveis estimados foram $1,045 \%$ de lisina digestível (0,972\% digestível ou 1,105\% total corrigido) e $0,982 \%$ (0,959\% digestível ou $1,090 \%$ total corrigido). Observados os valores da excreção e do balanço da energia, decorrentes do nível de lisina e da menor concentração de zinco, os valores estimados aproximam-se dos sugeridos na avaliação do desempenho para ganho de peso e conversão alimentar. Das dietas analisadas, as correções dos valores estimados pelas equações estão próximas à da dieta com 0,997\% de lisina digestível ou 1,134\% de lisina total.

Na dieta com 253 ppm de zinco quelato, o aumento de lisina digestível não influenciou a energia bruta excretada nem o balanço energético, mesmo que o consumo de matéria seca tenha sido afetado pelo nível de lisina. Esse efeito confirma as observações anteriores de que o excesso provável de lisina e demais nutrientes no nível maior de zinco tenha sido direcionado para deposição lipídica.

Considerando a melhor interação da menor concentração de zinco estudada com o nível de lisina digestível na dieta, os resultados deste estudo sugerem que a exigência de lisina digestível possa variar com a inclusão de zinco na dieta. Novos estudos, com menor inclusão de zinco na dieta poderão elucidar essas respostas no desempenho e metabolismo de frango de corte (macho) nessa fase do desenvolvimento.

\section{Conclusões}

A suplementação da dieta de frangos de corte com zinco quelato afeta as exigências de lisina digestível. Dos níveis aplicados, 0,977\% de lisina digestível ou 1,134\% de lisina total é o mais indicado para suprir as necessidades na fase dos 22 aos 42 dias de idade, recebendo 43 ppm de zinco. Considerando o rendimento de cortes, o nível de lisina digestível recomendável deve ser 1,002\% ou 1,139\% de lisina total, um pouco acima da indicação para ganho de peso e melhor conversão alimentar, independentemente da inclusão de zinco quelato. O maior nível de zinco não confere benefícios adicionais à lisina da dieta e aumenta a deposição de gordura corporal.

\section{Agradecimentos}

À Agroceres Ross, à Ajinomoto Biolatina Indústria e Comércio Ltda.

\section{Referências}

AOYAGI, S.; BAKER, D.H. Nutritional evaluation of a cooperlysine and zinc-lysine complexes for chicks. Poultry Science, v.72, n.1, p.16-171, 1993.

AZCONA, J.; SCHANG, M.; CORTAMIRA, O. [2003]. Nível de lisina nas rações de frangos de corte: Experimento 1 - 22 a 42 dias de idade, Experimento 2 - 36 a 49 dias de idade. Disponível em: <http://www.lisina.com.br> Acesso em: 21/3/2006.

BARTLETT, J.R.; SMITH, M.O. Effects of different levels of zinc on the performance and immunocompetence of broilers under heat stress. Poultry Science, v.82, n.10, p.1580-1588, 2003.

BARTOV, I.; PLAVNIK, I. Moderate excess of dietary protein increases breast meat yield of broilers chicks. Poultry Science, v.77, p.680-688, 1998.

BIRKETT, S.; LANGE, K. Limitation of conventional models and a conceptual framework for a nutrient flow representation of energy utilization by animals. British Journal Nutrition, v.86, p.647-659, 2001.

BORGES, A.F.; OLIVEIRA, R.F.M.; DONZELE, J.L. et al. Exigência de Lisina para frangos de corte machos no período de 22 a 42 dias de idade, mantidos em ambiente quente $\left(26^{\circ} \mathrm{C}\right)$. Revista Brasileira de Zootecnia, v.31, n.5, p.1993-2001, 2002.

BURRELL, A.L.; DOZIER, W.A.; DAVIS, A.J. et al. Responses of broilers to dietary zinc concentrations and sources in relation to environmental implications. British Poultry Science, v.45, n.2, p.225, 2004.

CAUWENBERGHE, S.V.; BURNHAM, D. New developments in amino acid and protein nutrition of poultry, as related to optimal performance and reduced nitrogen excretion. In: EUROPEAN SYMPOSIUM OF POULTRY NUTRITION, 13., 2001, Blankenberge, Belgium. Anais... Blankenberge, Belgium, 2001. p.141-149.

CHEN, M.D.; LIN, P.Y.; CHENG, V. et al. Zinc Supplementation AGGRAVATES BODY FAT ACCUMULATION IN GENETICALLY OBESE MICE AND DIETARY-OBESE MICE. Biological Trace Element Research, v.52, p.125-132, 1996.

CHENG, J.; KORNEGAY, E.T.; SCHELL, T. Influence of dietary lysine on the utilization of zinc from zinc sulfate and a zinclysine complex by young pigs. Journal of Animal Science, v.76, p.1064-1074, 1998.

CLAUS, R.; WEILER, U. Endocrine regulation of growth and metabolism in the pig: a review. Livestock Production Science, v.37, n.3, p.245-260, 1994.

EITS, R.M.; KWAKKEL, R.P.; VERSTEGEN, M.W.A. et al. Responses of broiler chickens to dietary protein: effects of early life protein nutrition on later responses. British Poultry Science, v.44, n.3, p.398, 2003.

FATUFE, A.A.; TIMMLER, R.; RODEHUTSCORD, M. Response to lysine intake in composition of body weight gain and efficiency of lysine utilization of growing male chickens from two genotypes. Poultry Science, v.83, n.8, p.1314-1324, 2004. 
HESS, J.B.; BILGILI, S.F.; PARSON, A.M. et al. Influence of complexed zinc products on live performance and carcass grade of broilers. Journal Applied Animal Research, v.19, p.49-60, 2001.

HUDSON, B.P.; DOZIER III, W.A.; WILSON, J.L. Broiler live performance response to dietary zinc source and the influence of zinc supplementation in broiler breeder diets. Animal Feed Science and Technology, v.118, n.3-4, p.329-335, 2005.

KIDD, M.T.; ANTHONY, N.B.; LEE, S.R. Progeny performance when dams and chicks are fed supplemental zinc. Poultry Science, v.71, p.1201-1206, 1992.

KOLLING, A.V.; KESSLER, A.M.; RIBEIRO, A.M.L. Desempenho e Composição corporal de frangos de corte alimentados com diferentes níveis de proteína e de aminoácidos ou com livre escolha das dietas. Revista Brasileira de Zootecnia, v.34, n.1, p.98-103, 2005.

LEESON, S.; ZUBAIR, A.K. Nutrition of the broiler chickens around the period of compensatory growth. Poultry Science, v.76, n.7, p.992-999, 1997.

NAMAZU, L.B.; KOBASHIGAWA, E.; ALBUQUERQUE, R. et al. Lisina digestível e Zn quelado para frangos de corte machos: desempenho e retenção de nitrogênio na fase pré-inicial. Revista Brasileira de Zootecnia, v.37, n.9, p.1634-1640, 2008.

ROSTAGNO, H.S.; ALBINO, L.F.T.; DONZELE, J.L. et al. Composição de alimentos e exigências nutricionais de aves e suínos. (Tabelas Brasileiras). Viçosa, MG: Imprensa Universitária, 2005. 186p.

SEBASTIAN, S.; TOUCHBURN, S.P.; CHAVEZ, E.R. et al. Apparent digestibility of protein and amino acids in broiler chickens fed a corn-soybean diet supplemented with microbial phytase. Poultry Science, v.76, n.12, p.1760-1769, 1997.

SKLAN, D.; NOY, Y. Catabolism and deposition of amino acids in growing chicks: effect of dietary supply. Poultry Science, v.83, n.6, p.952-961, 2004.
STATISTICAL ANALYSES SYSTEM - SAS. User's guide: statistics. 12.ed. New York: SCOTT, M.L. \& Associates, 2004. $1686 \mathrm{p}$.

SUSENBETH, A.; KEITEL, K. Partition of whole body protein in different body fractions and some constants in body composition in pigs. Livestock Production Science, v.20, n.1, p.37-52, 1988.

SWATSON, H.K.; GOUS, R.; IJI, P.A. et al. Effect of dietary protein level, amino acid balance and feeding level on growth, gastrointestinal tract, and mucosal structure of the small intestine in broiler chickens. Animal Research, v.51, p.501-515, 2002.

TALLMAN, D.L.; TAYLOR, C.G. Effects of dietary fat and zinc on adiposity, serum leptin and adipose fatty acid composition in C57BL/6J mice. The Journal of Nutritional Biochemistry, v.14, n.1, p.17-23, 2003.

TOLEDO, A.L.; TAKEARA, P.; KOBASHIGAWA, E. et al. Níveis dietéticos de lisina digestível para frangos de corte machos no período de 1 a 11 dias de idade: desempenho e composição corporal. Revista Brasileira de Zootecnia, v.36, n.4, p.1090-1096, 2007 (supl.).

TRINDADE NETO, M.A.; TAKEARA, P.; TOLEDO, A.L. et al. Níveis de lisina digestível para frangos de corte machos no período de 37 a 49 dias de idade. Revista Brasileira de Zootecnia, v.38, n.3, p.508-514, 2009.

VALÉRIO, S.R.; OLIVEIRA, R.F.M.; DONZELE, J.L. Níveis de lisina digestível em rações, mantendo ou não a relação aminoacídica, para frangos de corte de 22 a 42 dias de idade, sob condições de estresse por calor. Revista Brasileira de Zootecnia, v.32, n.2, p.372-382, 2003.

YAMAGUSHI, M.; OISHI, H.; SUKETA, Y. Zinc stimulation of bone protein synthesis in tissue culture. Activation of aminoacyltRNA synthetase. Biochemistry and Pharmacology, v.37, n.21, p. 4075-80, 1988. 